\title{
Phylogenetic characterisation of the genus Idiosepius (Cephalopoda; Idiosepiidae)
}

\author{
Janek von Byern ${ }^{1, *}$, Rainer Söller ${ }^{2}$, Gerhard Steiner ${ }^{3}$ \\ ${ }^{1}$ Cell Imaging and Ultrastructural Research Unit, Life Sciences, University of Vienna, 1090 Vienna, Austria \\ ${ }^{2}$ QIAGEN Hamburg GmbH, 22767 Hamburg, Germany \\ ${ }^{3}$ Department of Evolutionary Biology \& Emerging Focus: Molecular Phylogenetics, University of Vienna, 1090 Vienna, Austria
}

\begin{abstract}
The family Idiosepiidae is an atypical cephalopod group; the member species are the smallest cephalopods in body size, and their phylogenetic position with regard to the other cephalopods as well as the relationships within the genus Idiosepius remain controversial. Currently, 8 recognized species belong to Idiosepius, although the taxonomic position of I. macrocheir and $I$. thailandicus is uncertain: their diagnostic characters closely overlap with those of $I$. biserialis. To provide further information on the phylogenetic relationships of Idiosepius, 4 mitochondrial loci (12S rRNA, 16S rRNA and cytochrome $c$ oxidase subunits I and III) were analysed for all Idiosepius species and several populations. I. macrocheir and I. thailandicus nested within the African and the Indo-Pacific group of $I$. biserialis, respectively. This indicates that both species were incorrectly assigned to a single species, and that they rather represent junior synonyms of $I$. biserialis. Furthermore, the species $I$. biserialis itself exhibits considerable genetic variability: an African and Indo-Pacific region population was evident. Our results revealed 2 new aspects of Idiosepius: a population of $I$. biserialis from Japan appeared to be closely related to I. paradoxus, a species with 4 rows of suckers on the tentacular club. In contrast, I. paradoxus from Okinawa Island, also considered a 4-rowed species, showed strong congruence on the phylogenetic and taxonomic level with the 2-rowed species $I$. biserialis. This congruence leads to the hypothesis that climatic conditions, rather than habitat preference or geographical barriers, support the structuring of Idiosepius populations.
\end{abstract}

KEY WORDS: Holotype analysis · Classification · Species characterisation · Mollusca Resale or republication not permitted without written consent of the publisher

\section{INTRODUCTION}

The genus Idiosepius Steenstrup, 1881 comprises the smallest species among cephalopods, with a mantle length less than $6 \mathrm{~mm}$ in females and $3 \mathrm{~mm}$ in males (von Byern \& Klepal 2010). A conspicuous morphological character of this family is the adhesive organ (also known as the adhesive gland), which is restricted to the posterior part of the dorsal mantle and fin region (Steenstrup 1881, Sasaki 1921, von Byern et al. 2008, Cyran et al. 2011).

Idiosepiids have been studied for many interesting features, including life history strategies, physiology, behaviour and adhesive organ morphology (Nabhitabhata 1998, Kasugai 2000, Shigeno \& Yamamoto
2002, von Byern et al. 2008, Cyran \& von Byern 2010). Nonetheless, the phylogenetic placement of the Idiosepiidae remains contentious. Two competing hypotheses have been proposed. The first places the genus into the Sepiidae (Clarke 1988, von Boletzky 1995, Carlini \& Graves 1999, Lindgren et al. 2004, Strugnell et al. 2005, Akasaki et al. 2006), whereas the second argues for the Teuthidae (Bonnaud et al. 1996, 1997, 2005, Carlini et al. 2000, Takumiya et al. 2005).

Moreover, the number of species that the genus Idiosepius comprises also remains unclear. Jereb \& Roper (2005) proposed 8 species: I. biserialis Voss, 1962; I. macrocheir Voss, 1962; I. minimus (D'Orbigny \& de Ferussac 1848); I. notoides Berry, 1921; I. paradoxus 
Ortmann, 1888; I. picteti (Joubin, 1894); I. pygmaeus Steenstrup, 1881 (= I. pygmaeus hebereri Grimpe, 1931) and $I$. thailandicus Chotiyaputta et al., 1991. The geographical distribution of these species is large (Fig. 1), from Japan to the Indo-Pacific region including Australia and Tasmania as well as Mozambique (incorrectly annotated as South Africa by Voss 1962).

Of these 8 species, 6 are represented in a systematic key proposed by Nesis (1987). The species are characterised by the arrangement of suckers on the tentacular club (Idiosepius biserialis with 2 rows, I. notoides, I. macrocheir, I. paradoxus, I. picteti and I. pygmaeus with 4 rows) and the number of suckers on the male hectocotylus (Nesis 1987). I. thailandicus was described afterwards (Chotiyaputta et al. 1991), and the holotype material of I. minimus is lost, thus its systematic position can no longer be verified. These 2 species are therefore missing in the key.

The discovery of Idiosepius thailandicus (Chotiyaputta et al. 1991) in Thai waters along with $I$. biserialis (Hylleberg \& Nateewathana1991a) raises questions about the validity of the systematic key. These 2 species resemble each other closely by a biserial sucker arrangement on the tentacular clubs and the same number of suckers on the hectocotylised arms. Chotiyaputta et al. (1991) instead proposed to differentiate the 2 species by mantle length (I. thailandicus is slightly smaller than $I$. biserialis) and sucker ultrastructure. It remains unresolved whether these 2 morphological features (mantle length and sucker ultrastructure) are reliable characters for other species of the genus.

To compare these features, von Byern \& Klepal (2010) conducted a morphological re-examination of all taxonomic characters proposed by Nesis (1987) and Chotiyaputta et al. (1991) in all nominal Idiosepius species. Their results support a revision of the systematic key of Nesis (1987). Von Byern \& Klepal (2010) proposed that species should be characterised by the shape of the hectocotylus and its appendages rather than by the sucker arrangement on the tentacular club. Based on this information, the systematic position of $I$. thailandicus is uncertain because it does not differ from $I$. biserialis in mantle length, form or number of suckers on the hectocotyli and tentacular clubs, or in other morphological attributes (von Byern $\&$ Klepal 2010). That evaluation also supports a revision of the systematic status of I. macrocheir. Based on the number of suckers on the tentacular club, $I$. macrocheir belongs to the 2-rowed rather than to the 4 -rowed group; its 4-rowed arrangement appears to be an artefact of the fixation process (von Byern \& Klepal 2010).

Given all of these major differences in morphological characters and systematic placement of individual species, our aim was to provide information on the phylogenetic relationship of the Idiosepiidae based on molecular data.

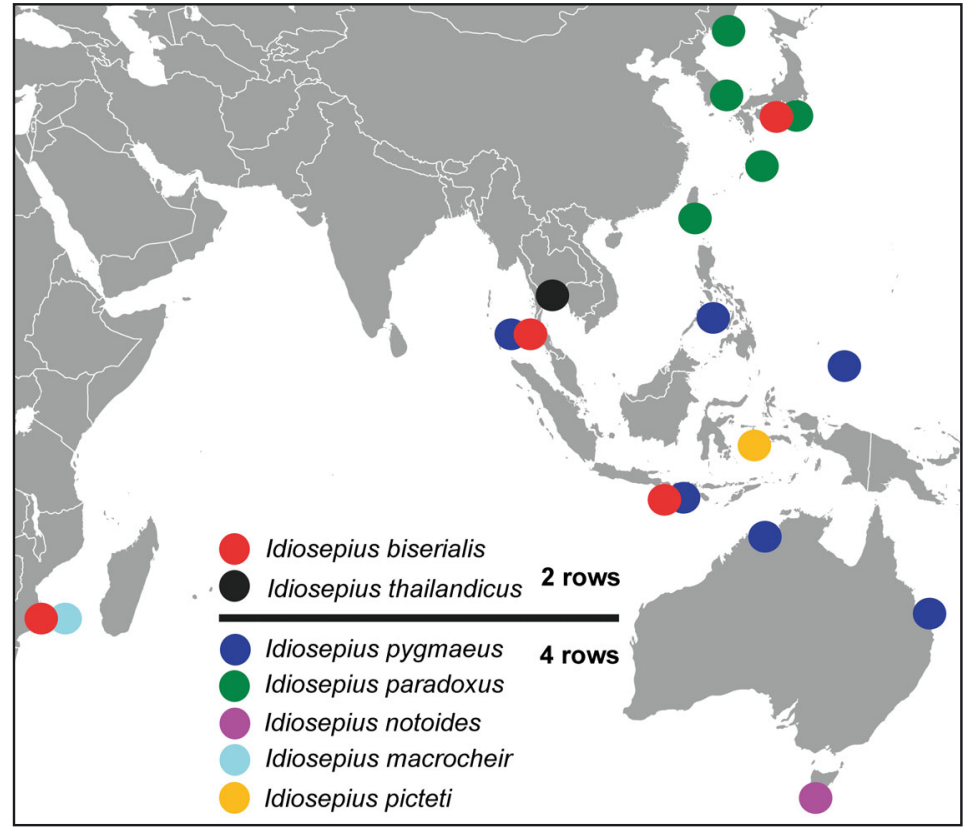

Fig. 1. Geographical distribution and collection sites for all nominal Idiosepius spp. according to Nesis (1987). 'Rows' refers to the arrangement of suckers on the tentacular club

\section{MATERIALS AND METHODS}

In total, 88 specimens of 7 nominal taxa from different locations (Idiosepius biserialis $\mathrm{n}=34 ; I$. macrocheir $\mathrm{n}=2 ;$ I. notoides $\mathrm{n}=4$; I. paradoxus $\mathrm{n}=20$; I. picteti $\mathrm{n}=1$; I. pygmaeus $\mathrm{n}=21$ and $I$. thailandicus $\mathrm{n}=6$ ) were obtained for the analysis. A detailed description of the collected specimens and their locations with latitude and longitude data as well information of all known localities are given in Table S1 in the supplement at www.intres.com/articles/suppl/b017p019_supp.pdf

It was possible to extract DNA from the holotype sample of Idiosepius picteti, and the animal was therefore used for the phylogenetic analysis. However, the long storage (>100 yr) and/or fixation (10\% formalin) modified or damaged its DNA, and it was not possible to correctly allocate this species to the other representatives of the family. We retained the species in the analysis to docu- 
ment our attempts and initial ideas about its possible allocations. More material or other gene loci need to be analysed to verify the systematic status of $I$. picteti.

\section{DNA extraction, amplification and sequencing}

Living specimens were fixed in $90 \%$ ethanol. For the DNA extraction, muscle tissue (without the epidermis and chromatophores) from the arm or mantle area was used and washed several times in distilled water to eliminate the ethanol. Total DNA was isolated with a DNeasy Tissue Kit (Qiagen). Once isolated, 1 to $10 \mathrm{ng}$ of DNA were used for polymerase chain reaction (PCR), performed with MangoTaq DNA Polymerase (Bioline). Four different loci were analysed, i.e. partial sequences of the genes for $12 \mathrm{~S}$ rRNA (386 bp in total), 16S rRNA (505 bp in total), cytochrome $c$ oxidase subunit I (COI; $640 \mathrm{bp}$ in total) and subunit III (COIII; $657 \mathrm{bp}$ in total). Specific primer sets were used to amplify each of the 4 loci (Table 1). Additional internal primers were constructed to sequence samples of the type material. The PCR protocol is summarized in Table 2; for 16S rRNA, 2 PCR protocols were used.

PCR products were purified with the peqGold Cycle-pure Kit (Peqlab) and sequenced on an Applied Biosystems automated capillary sequencer (model 3130xl) using Applied Biosystems Big Dye v3.1.
Table 1. Primers used for PCR amplification and sequencing. Primers were used in various combinations of forward (f) and reverse (r) primers to provide overlapping fragments, thus increasing the efficiency of some PCR amplifications. All possible primer combinations shown here were effective and did not lead to a primer dimerization

\begin{tabular}{|ll|}
\hline Primer & Sequence (5'-3') \\
\hline COI & GGT CAA CAA ATC ATA AAG ATA TTG G \\
COI & TAA ACT TCA GGG TGA CCA AAA AAT CA \\
COI-140f & GTC GTT GTA ACA GCT CAC GG \\
COI-140r & CCG TGA GCT GTT ACA ACG AC \\
COI-200f & GGA TTT GGG AAT TGA TTG GTA CC \\
COI-200r & GGT ACC AAT CAA TTC CCA AAT CC \\
COI-320f & GGC AGT TGA AAG AGG GGC AG \\
COI-320r & CTG CCC CTC TTT CAA CTG CC \\
COI-480f & CGA TGA GAA GGT TTA CAA ATA GAA CG \\
COI-480r & CGT TCT ATT TGT AAA CCT TCT CAT CG \\
COI-580r & ATT GCA CCA GCA AGT ACA GG \\
COIII-f & CAT TTA GTT GAT CCT AGG CCT TGA CC \\
COIII-r & CAA ACC ACA TCT ACA AAA TGC CAA TAT \\
COIII-110f & CTC CAA TGA TGA CGA GAT AT \\
COII-110r & ATA TCT CGT CAT CAT TGG AG \\
COIII-260f & CAG AAC TAG GWG CCT GTT GAC \\
COIII-260r & GTC AAC AGG CWC CTA GTT CTG \\
COIII-360f & CAG GCG TWA SGG TAA CAT GAG \\
COIII-360r & CTC ATG TTA CCS TWA CGC CTG \\
COIII-460f & CAA GCA GAR GAA TAT ATA GAA GC \\
COIII-460r & GCT TCT ATA TAT TCY TCT GCT TG \\
12S rRNA-f & AAA CTA GGA TTA GAT ACC CTA TTA T \\
12S rRNA-r & AAG AGC GAC GGG CGA TGT GT \\
12S rRNA-180f & CTG ATG ACA GAA ATA TAC AAA CTG \\
12S rRNA-280r & CCT TTC AGG GGA GTT TGC \\
16S rRNA-f & CGC CTG TTT ATC AAA AAC AT \\
16S rRNA-r & CTC CGG TTT GAA CTC AGA TCA \\
16S rRNA-100f & GAG GCT AGA ATG AAT GGT TTG ACG \\
16S rRNA-100r & CGT CAA ACC ATT CAT TCT AGC CTC \\
16S rRNA-200f & GAC GAG AAG ACC CTA GTG AGC \\
16S rRNA-200r & GCT CAC TAG GGT CTT CTC GTC \\
16S rRNA-360f & GTT ACC ATA GGG ATA ACA GCG \\
16S rRNA-360r & CGC TGT TAT CCC TAT GGT AAC \\
& \\
& \\
\hline
\end{tabular}

\section{Phylogenetic analysis}

Sequences were aligned with ClustalX Version 1.83 (Thompson et al. 1997), with no gaps or ambiguities in the alignments of any sequences. All variable sites were reconfirmed by visual inspection of the sequence data and verified on both strands. GenBank accession numbers for all sequences are provided in Table S2 in the supplement. A total of 90 aligned sequences of Idiosepius were used, with Sepia officinalis (AB 193808.1; AB 193804.1; AB 240155.1) as the outgroup. Since the phylogenetic placement of Idiosepiidae within the cephalopods is not clarified (see 'Introduction'),

Table 2. PCR protocols for the 4 gene loci; for 16S rRNA, 2 different protocols were used

\begin{tabular}{|c|c|c|c|c|c|c|c|c|c|c|c|c|}
\hline \multirow[b]{2}{*}{$\begin{array}{l}\text { Initial } \\
\text { denaturation }\end{array}$} & \multicolumn{3}{|c|}{ 12S rRNA } & \multicolumn{6}{|c|}{$\longrightarrow$ 16S rRNA } & \multicolumn{3}{|c|}{ COI and COIII } \\
\hline & $2 \min$ & $94^{\circ} \mathrm{C}$ & & $2 \min$ & $94^{\circ} \mathrm{C}$ & & $2 \min$ & $94^{\circ} \mathrm{C}$ & & $2 \min$ & $94^{\circ} \mathrm{C}$ & \\
\hline Denaturation & $25 \mathrm{~s}$ & $94^{\circ} \mathrm{C}$ & & $20 \mathrm{~s}$ & $94^{\circ} \mathrm{C}$ & & $20 \mathrm{~s}$ & $94^{\circ} \mathrm{C}$ & & $2 \min$ & $94^{\circ} \mathrm{C}$ & \\
\hline Annealing & $30 \mathrm{~s}$ & $46^{\circ} \mathrm{C}$ & 35 cycles & $20 \mathrm{~s}$ & $50^{\circ} \mathrm{C}$ & 15 cycles & $20 s$ & $43^{\circ} \mathrm{C}$ & 20 cycles & $10 \mathrm{~s}$ & $42-45^{\circ} \mathrm{C}^{\mathrm{a}}$ & 36 cycles \\
\hline Elongation & $40 \mathrm{~s}$ & $72^{\circ} \mathrm{C}$ & & $40 \mathrm{~s}$ & $72^{\circ} \mathrm{C}$ & & $40 \mathrm{~s}$ & $72^{\circ} \mathrm{C}$ & & $1 \min 45 \mathrm{~s}$ & $72^{\circ} \mathrm{C}$ & \\
\hline
\end{tabular}


it made no difference whether we used Sepiidae or Teuthidae species as the outgroup because the relationship within Idiosepius remains constant.

Maximum parsimony (MP) analyses of the aligned data with unordered and equally weighted characters, 100 random addition replicates and tree bisection and reconnection (TBR) branch swapping were conducted in PAUP (4.0b10) (Swofford 2002). A maximum of 100 most parsimonious trees were saved for each replicate, and the resulting trees subsequently submitted to another round of TBR branch swapping. Branch support was assessed by bootstrapping (1000 replicates) using the heuristic search option and TBR branch swapping.

Maximum likelihood (ML) searches of the individual genes were started with the neighbor-joining (NJ) tree and subsequent TBR branch swapping, using the model and parameters returned by the Akaike Information Criterion (AIC) in MODELTEST 3.06 (Posada \& Crandall 1998). A Bayesian analysis with MRBAYES 3.1.2 (Huelsenbeck \& Ronquist 2001, Ronquist \& Huelsenbeck 2003) was performed on the data, with individual partitions for each gene. Individual MODELTEST runs for each data partition returned the GTR $+\Gamma+\mathrm{I}$ model for $\mathrm{COI}$ and $16 \mathrm{~S}$, which we also applied to the COIII data (TIM+ $++\mathrm{I}$ suggested by AIC). The Kimura81 model with unequal base frequencies $+\Gamma+\mathrm{I}$ was suggested for the $12 \mathrm{~S}$ partition. The chains were run for 5 million generations, a sampling frequency of 100 and a burn-in of 5000 after visual assessment of chain convergence.
Idiosepius notoides appeared as a monophyletic sister group to the other members of the genus in all analyses. We therefore selected this clade as the outgroup instead of Sepia and ran the above analyses again to avoid long branch attraction artefacts due to the long branches of Sepia. Eliminating identical sequences from the data set resulted in 46 unique Idiosepius sequences.

\section{RESULTS}

Overall, the analyses of the 4 mitochondrial loci were suitable to differentiate between the species and population level for Idiosepius. The phylogenetic analyses of the partial 12S rRNA, 16S rRNA, COI and COIII genes clearly revealed that I. notoides, I. pygmaeus and I. picteti were monophyletic (all analyses), whereas I. biserialis and I. paradoxus were polyphyletic for the same analysis.

Similar tree topologies (Fig. 2) resulted from the combined phylogenetic analyses of all 4 gene loci
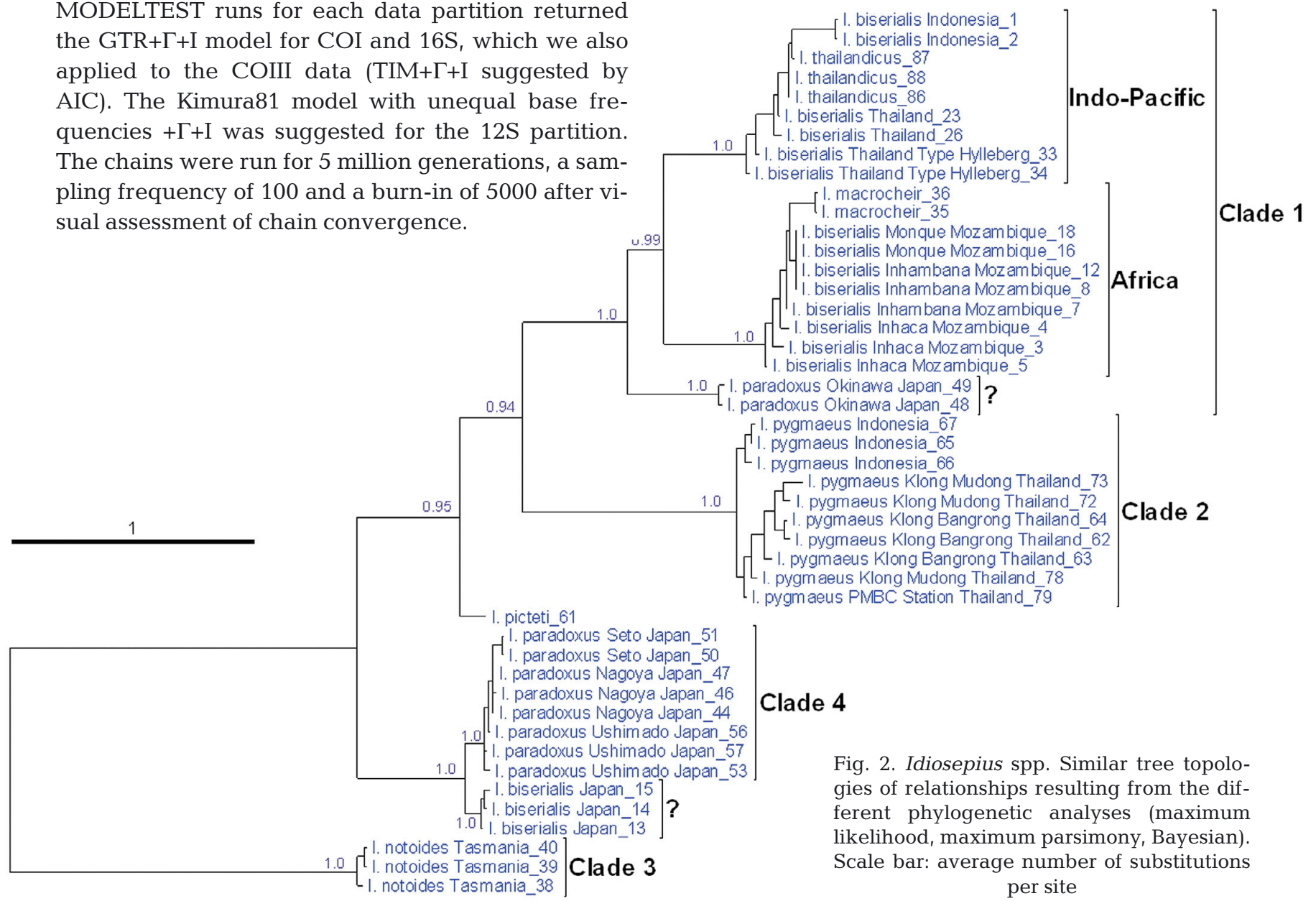

I. pygmaeus Indonesia_ $\overline{6} 7$

-1. pygmaeus Indonesia_65

- . pygmaeus Indonesia 66

$-L_{1}$. pygmaeus Klong Mudong Thailand 73

I. pygmaeus Klong Mudong Thailand_ $\overline{72}$

LI. pygmaeus Klong Bangrong Thailand_64

L pymaeus Klong Bangrong Thailand 63

I. pygmaeus Klong Mudong Thailand 78

I. pygmaeus PMBC Station Thailand_ $\overline{7} 9$

I. notoides Tasmania_38

\section{Clade 4}

Fig. 2. Idiosepius spp. Similar tree topologies of relationships resulting from the different phylogenetic analyses (maximum likelihood, maximum parsimony, Bayesian). Scale bar: average number of substitutions per site 
using NJ, MP, ML and Bayesian inference. The MP analysis of the combined dataset was stopped at 1.5 million most parsimonious trees (tree length 888, consistency index [CI] 0.6036, rescaled consistency index $[R C]$ 0.575). The strict consensus tree showed polytomies within the monophyletic species clades only. Genetic distances between members of different clades ranged from 5 to $13 \%$, whereas distances within Clades 2 to 4 did not exceed $2 \%$. The greatest intra-clade distances of up to $5 \%$ occurred in Clade 1 between Indian Ocean and Pacific individuals of Idiosepius biserialis.

Four well-supported clades were consistently recovered. The 2-rowed species Idiosepius biserialis (Clade 1) was robustly subdivided into 2 populations: the African group consisting of $I$. biserialis from the different locations in Mozambique, and the IndoPacific group comprising all $I$. biserialis specimens from Thailand and Indonesia. I. macrocheir nested within the African group of $I$. biserialis, whereas $I$. thailandicus nested within the Indo-Pacific group. Specimens of I. paradoxus from Okinawa Island (Japan) formed a sister group to I. thailandicus, I. macrocheir and $I$. biserialis (African and Indo-Pacific group). The 4-rowed group was represented by I. pygmaeus (Clade 2) and I. notoides (Clade 3). Clade 4 comprised specimens of I. paradoxus from different locations (Nagoya, Ushimado and Seto Island, Japan) as well as individuals of $I$. biserialis from Japan. The position of the type specimen of I. picteti was unstable and varied with markers and analysis methods (Fig. 3).

Comparison of the Bayesian data of each gene locus indicated divergences between the Idiosepius biserialis populations. In the $16 \mathrm{~S}$ and COIII analyses, the 4 clades were well represented (Fig. S1A,B in the supplement), while in the $12 \mathrm{~S}$ and COI analyses, the genus was geographically divided: Africa (with I. biserialis from Africa and I. macrocheir), Indo-Pacific (comprising I. biserialis Indo-Pacific, I. pygmaeus, I. paradoxus Okinawa, I. picteti and I. thailandicus), Japan (I. biserialis from Japan and I. paradoxus) and the Tasmanian group (I. notoides; Fig. S1C,D in the supplement).
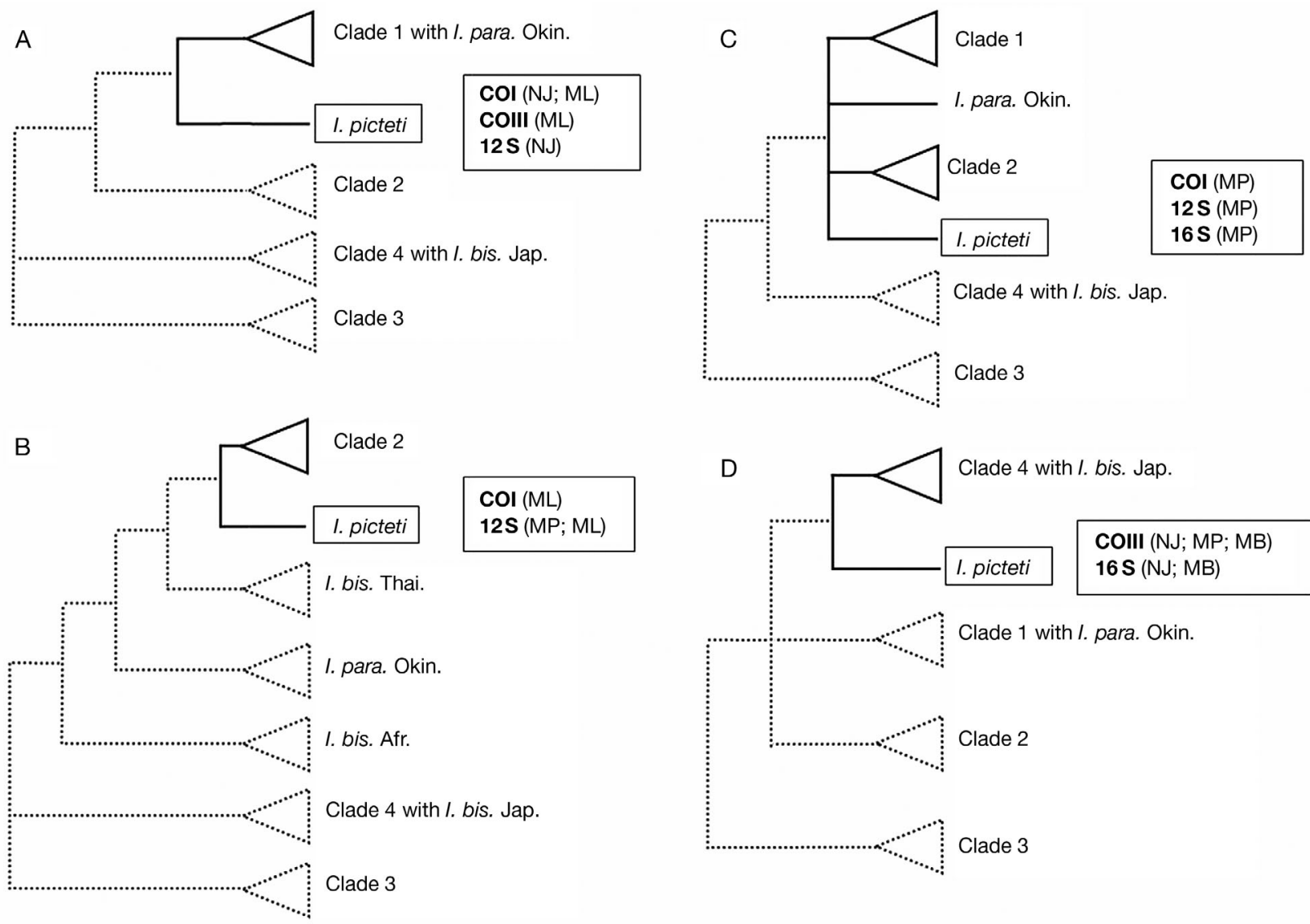

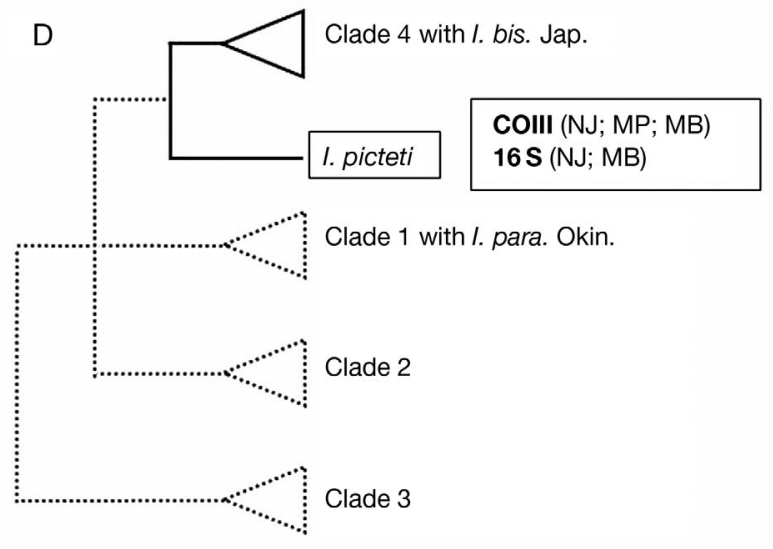

Fig. 3. Idiosepius picteti. (A-D) Cladograms representing its systematic position in the phylogenetic analysis using all 4 gene loci and neighbour joining (NJ), maximum parsimony (MP), maximum likelihood (ML) and Bayesian (MB) inference. I. para: I. paradoxus; I. bis.: I. biserialis; Okin.: Okinawa; Jap.: Japan; Thai.: Thailand; Afr.: Africa 
Characterisation of COI and COIII in the African population of Idiosepius biserialis indicated a slight divergence for $I$. macrocheir, which was not observed using 12S and 16S rRNA genes (Fig. S1B,D in the supplement).

\section{DISCUSSION}

Since the earlier taxonomic study by von Byern \& Klepal (2010) raised questions about the validity of Idiosepius thailandicus and I. macrocheir, the aim of our study was to re-evaluate the phylogenetic relationships among all nominal Idiosepius species.

\section{Idiosepius thailandicus}

As hypothesized earlier (Nabhitabhata \& Suwanmala 2008, von Byern \& Klepal 2010), the systematic position of $I$. thailandicus is uncertain. Based on the taxonomic characters proposed by Nesis (1987) and von Byern \& Klepal (2010), it is impossible to distinguish I. biserialis and I. thailandicus. Moreover, cross-mating experiments have shown that both species mate with each other and produce fertilized eggs (Nabhitabhata \& Suwanmala 2008), whereas I. biserialis and $I$. pygmaeus do not show mutual mating behaviour.

The present phylogenetic data confirm that Idiosepius thailandicus is robustly nested within the Indo-Pacific group of $I$. biserialis and support the hypothesis that $I$. thailandicus represents a junior synonym of $I$. biserialis. However, both species are differently distributed geographically along the coasts of Thailand: I. thailandicus in the Gulf of Thailand and $I$. biserialis in the Andaman Sea. This raises the question whether the 2 species are able to come together in the same area. Moreover, it is doubtful whether both species occupy the same habitat, and the habitat preference of $I$. thailandicus is uncertain. While we found the species exclusively near mangrove roots in the eastern part of Thailand (Chontaburi province), the type material was collected by Chotiyaputta et al. (1991) with a push net from 2 to $5 \mathrm{~m}$ in the estuary of the Donsak River in the southern province of Surat Thani. The depth and collection method point to a sea grass bed habitat, but the original authors could not be contacted to clarify this point. Moreover, it cannot be excluded that the 'mangrove' specimens we found in Chontaburi province are individuals that drifted into this habitat; we never controlled the estuary for possible sea grass beds.
The situation is clearer for $I$. biserialis: all specimens were collected exclusively in sea grass beds (Suwanmala et al. 2006).

Finally, the geographical distribution and habitat preference of both species remain poorly known and will require further investigation. Nonetheless, our study as well as the taxonomic characterisation by von Byern \& Klepal (2010) and cross-mating experiments by Nabhitabhata \& Suwanmala (2008) strongly indicate that Idiosepius thailandicus was incorrectly characterised as a separate species and actually represents a junior synonym of $I$. biserialis.

\section{Idiosepius macrocheir}

Although Voss (1962) characterised I. macrocheir as a 4-rowed species, morphological re-evaluations of this systematic character (Nürnberger et al. 2006, von Byern \& Klepal 2010) as well as our present data clearly indicate that I. macrocheir is related to the 2rowed instead of the 4-rowed group. Additionally, since Voss (1962), no further individuals with a 4rowed arrangement of suckers on the tentacular clubs have been found in Mozambican waters, although several collection expeditions by the South African Museum in this region have been undertaken in the past. Moreover, the paratypes SAM 185 \& 186 of $I$. macrocheir were collected in the same area and habitat where we recently caught specimens of $I$. biserialis for this research. Our molecular phylogenetic analysis as well as the morphological data provide strong evidence that I. macrocheir resembles $I$. biserialis and may also be a junior synonym, as proposed for I. thailandicus.

\section{Idiosepius picteti}

In addition to the uncertain phylogenetic relationships of I. thailandicus and I. macrocheir, the systematic position of $I$. picteti is doubtful. There is evidence that the handling and fixation of the holotype sample not only led to a mis-arrangement of the suckers on the tentacular clubs but also considerably changed its body form. A non-anaesthetised specimen of $I$. pygmaeus (NHMW no.103225) collected in Indonesia became deformed due to fixation (von Byern \& Klepal 2007) and showed the same shape as the holotype specimen of $I$. picteti (Joubin 1894). Apart from this coincident similarity, I. picteti showed close congruence to I. pygmaeus in the shape and number of suckers on the hectocotylised arms (von Byern \& 
Klepal 2010). This led to the hypothesis that I. picteti was likewise incorrectly classified as a single species and rather resembles a subspecies of I. pygmaeus, as already described for I. pygmaeus hebereri (Grimpe 1931).

Our phylogenetic analyses failed to provide a clear relationship of Idiosepius picteti to I. pygmaeus or any other Idiosepius species, as shown in Fig. 2. According to the different phylogenetic analyses of the 4 gene loci, the phylogenetic position of I. picteti remains uncertain because the relationship with the 2-rowed group contrasts with the morphological data. The reason for the incorrect allocation may reflect damage of the 4 gene loci caused by the long storage and/or fixation. Despite 5 amplification and sequencing runs, the data and analysis remained the same. More material or other gene loci need to be analysed to verify with certainty the systematic status of I. picteti.

\section{Idiosepius biserialis}

Our molecular phylogenetic analyses clearly indicated genetic variability coinciding with geographic isolation among the $I$. biserialis populations sampled. This variability, however, could not be determined based on taxonomic characters (von Byern \& Klepal 2010) or habitat preferences (see Table S1 in the supplement). Specimens of I. biserialis from Japan were morphologically classified to the 2-rowed group (von Byern \& Klepal 2010) and appeared to be closely related to the 4-rowed species I. paradoxus. This phylogenetic distinctiveness compared to individuals from Africa and the Indo-Pacific cannot be attributed to geographic diversification, because $I$. biserialis from Japan should then still be closer to the individuals of Clade 1. We currently have no explanation for this phylogenetic distinctiveness. One obvious habitat difference of $I$. biserialis in Japan from that of the African and Indo-Pacific population is water temperature. The Japanese population remains in cool temperature zones (water temperature $\leq 15^{\circ} \mathrm{C}$ ), while the African and Indo-Pacific specimens occur in tropical waters $\left(\geq 25^{\circ} \mathrm{C}\right)$. Temperature seems to be responsible only for species migration, but it could also potentially explain local adaptation and future speciation. Unfortunately, the $I$. biserialis samples collected in Japan were occasional findings; the precise area and habitat in which the animals normally occur remain unknown. More individuals are needed to verify their taxonomic characters and indicate their relationship to I. biserialis and/or I. paradoxus.

\section{Idiosepius paradoxus, Okinawa Island}

A situation similar to that of $I$. biserialis from Japan exists for I. paradoxus from Okinawa Island. Based on the geographical assignment of Okinawa Island to Japan, these individuals were defined as I. paradoxus. Based on the number of suckers on the tentacular clubs, which seems to be the only possible way to taxonomically differentiate the species (von Byern \& Klepal 2010), the individuals from Okinawa Island (average $40 \pm 6$ suckers) were more closely related to the 2- ( $\leq 46$ suckers) than to the 4 -rowed species $(\leq 83$ suckers). The investigated animals, however, were exclusively females, precluding a taxonomic classification based on the hectocotylised fourth arm pair as proposed by the systematic key of Nesis (1987).

The current phylogenetic analyses also indicate a closer relationship of Okinawa Island Idiosepius paradoxus to $I$. biserialis than to I. paradoxus from mainland Japan. In our opinion, this mistake was made solely because of the geographical assignment of Okinawa Island to Japan. A larger sample collection of this population is planned in order to provide more information on their taxonomic characters and to classify the specimen from Okinawa Island clearly as I. biserialis or I. paradoxus.

\section{Geographical distribution and dispersal}

It remains fascinating how these animals - miniature in size, extremely short-lived $\left( \pm 150 \mathrm{~d}_{\text {; }}\right.$ Jackson 1988, Sato et al. 2008) and with a relatively strict inshore habitat preference (see Table S1 in the supplement) - could exhibit such a huge population range. We know from incidental observations that water temperature rather than geographical barriers or habitat preferences seem to affect animal migration/limitation. Populations of Idiosepius pygmaeus occur in the northern and north-eastern part of Australia, whereas I. notoides exclusively inhabit the southern part of Australia and Tasmania. The records show that these 2 species never overlap but are strictly separated by the warmer current off the coast of Queensland (Norman \& Reid 2000). Seasonal observations by Sato et al. (2009) confirmed that individuals of $I$. paradoxus are transported with the warm water to the north of Japan, but are not able to survive the cold winter there. Unexpectedly, I. paradoxus was observed in Russian waters (Nesis et al. $2002 \mathrm{~b}$ ) due to the warming of surface waters in Peter the Great Bay. This indicates that the animals can move 1000 km, e.g. though the Japan Sea, up to Rus- 
sia within less than 6 mo. Nonetheless, this migration distance is small compared to the distance which the smallest species, I. biserialis, overcame: from Africa through the Indo-Pacific to Japan.

Acknowledgements. We thank our entire national and international partner group for their support and cooperation during the stays. Their experience and knowledge allowed the official collection of the animals used in this research project. We are grateful to the following colleagues for providing type material: Idiosepius biserialis from Thailand (PMBC 7957) was loaned by J. Hylleberg and S. Bussarawit from the Phuket Marine Biological Station (PMBC). Type material of I. macrocheir (SAM 185 and SAM 186) was loaned by M. Compagno-Roeleveld from the South African Museum (SAM), Cape Town. Type material of $I$. thailandicus (NSMT-Mo 69624 No. 4) was loaned by T. Kubodera from the National Science Museum, Tokyo. Type material of I. picteti (M 3/75 747/27) was loaned by Y. Finet from the Muséum d'Histoire Naturelle, Geneva. Specimens of I. paradoxus from Okinawa Island, Japan, were given by Y. Ikeda and N. Kaneko from the University of the Ryukyus, Okinawa. Special thanks to late M. Compagno-Roeleveld, who helped us to collect specimens in Mozambique and provided the type material from the SAM. Her untimely death is very sad and a setback for research on cephalopods. We thank $\mathrm{H}$. Dreher, former member of the Dept. of Evolutionary Biology \& Emerging Focus: Molecular Phylogenetics, University of Vienna, for assistance and expertise during PCR. We greatly appreciate the editorial assistance of W. Klepal, Research Unit Cell Imaging and Ultrastructural, Faculty of Life Sciences, University of Vienna, and M. Stachowitsch from the University of Vienna, Dept. of Marine Biology. This work was funded by the Austrian Science Fund (FWF, Project No. P 17193 - B 12). Collection in Japan was promoted by the Japan Society for the Promotion of Science (JSPS, Grant No. 04567).

\section{LITERATURE CITED}

Adam W (1986) La radula et les mandibules de quelques espéces d'Idiosepius Steenstrup, 1881 (Mollusca Cephalopoda Decapoda). Bull Inst R Sci Nat Belg Biol 56:149-154

Akasaki T, Nikaido M, Tsuchiya K, Segawa S, Hasegawa M, Okada N (2006) Extensive mitochondrial gene arrangements in coleoid Cephalopoda and their phylogenetic implications. Mol Phylogenet Evol 38:648-658

Appellöf A (1898) Cephalopoden von Ternate. Abh Senckenb Natforsch Ges 24:570-637

Appellöf A (1899) Cephalopoden von Ternate 1. Verzeichnis der von Professor Kükenthal gesammelten Arten. 2. Untersuchungen über Idiosepius, Sepiadarium und verwandte Formen. Zool Centralbl VI:309-312

Berry SS (1921a) A review of the cephalopod genera Sepioloidea, Sepiadarium, and Idiosepius. Rec South Aust Mus 1:347-364

Berry SS (1921b) Cephalopods of the genera Sepiolidea, Sepiadarium, and Idiosepius. Philipp J Sci 47:39-55

Bonnaud L, Boucher-Rodoni R, Monnerot M (1996) Relationship of some coleoid cephalopods established by 3 ' end of the 16S rDNA and cytochrome oxidase III gene sequence comparison. Am Malacol Bull 12:87-90
Bonnaud L, Boucher-Rodoni R, Monnerot M (1997) Phylogeny of cephalopods inferred from mitochondrial DNA sequences. Mol Phylogenet Evol 7:44-54

Bonnaud L, Pichon D, Boucher-Rodoni R (2005) Molecular approach of Decabrachia phylogeny: Is Idiosepius definitely not a sepiolid? Res Bull Phuket Mar Biol Cent 66:203-212

Burn R (1959) Molluscan field notes - Part 3. Vic Nat 75 : 179-181

Carlini DB, Graves JE (1999) Phylogenetic analysis of cytochrome c oxidase I sequences to determine higherlevel relationships within the coleoid cephalopods. Bull Mar Sci 64:57-76

Carlini DB, Reece KS, Graves JE (2000) Actin gene family evolution and the phylogeny of coleoid cephalopods (Mollusca: Cephalopoda). Mol Biol Evol 17:1353-1370

Chotiyaputta C, Okutani T, Chaitiamvong S (1991) A new pygmy cuttlefish from the Gulf of Thailand Idiosepius thailandicus n. sp. (Cephalopoda: Idiosepiidae). Venus (Tokyo) 50:165-174

Clarke MR (1988) Evolution of recent cephalopods: a brief review. In: Clarke MR, Trueman ER (eds) The Mollusca Vol 12: paleontology and neoontology of cephalopods. Academic Press, New York, NY, p 331-340

Cyran N, von Byern J (2010) Characterization of the adhesive systems in cephalopods. In: von Byern J, Grunwald I (eds) Biological adhesive systems: from nature to technical and medical application. Springer Verlag, Vienna, p 61-66

Cyran N, Klepal W, von Byern J (2011) Ultrastructural characterization of the adhesive organ of Idiosepius biserialis and Idiosepius pygmaeus (Mollusca, Cephalopoda). J Mar Biol Assoc UK 91:1499-1510

D'Orbigny ACV, de Ferussac A (1848) Histoire naturelle generale et particuliere des cephalopodes acetabuliferes, vivantes et fossiles. Libraire de L'Academie Nationale de Medecine, Paris

> Eyster LS, van Camp LM (2003) Extracellular lipid droplets in Idiosepius notoides, the southern pygmy squid. Biol Bull (Woods Hole) 205:47-53

Grimpe G (1931) Teuthologische Mitteilungen XIII. Über die Cephalopoden der Sunda-Expedition Rensch. Zool Anz 95:149-174

Huelsenbeck JP, Ronquist F (2001) MRBAYES: Bayesian inference of phylogenetic trees. Bioinformatics 17:754-755

Hylleberg J, Nateewathana A (1991a) Morphology, internal anatomy, and biometrics of the cephalopod Idiosepius biserialis Voss, 1962. A new record for the Andaman Sea. Res Bull Phuket Mar Biol Cent 56:1-9

Hylleberg J, Nateewathana A (1991b) Redescription of Idiosepius pygmaeus Steenstrup, 1881 (Cephalopoda: Idiosepiidae), with mention of additional morphological characters. Res Bull Phuket Mar Biol Cent 55:33-42

Jackson GD (1988) The use of statolith microstructures to analyse life-history events in the small tropical cephalopod Idiosepius pygmaeus. Fish Bull 87:265-272

Jereb P, Roper CFE (2005) Cephalopods of the world-an annotated and illustrated catalogue of cephalopod species known to date. No. 4, Vol 1: chambered nautiluses and sepioids (Nautilidae, Sepiidae, Sepiolidae, Sepiadariidae, Idiosepiidae and Spirulidae). Food and Agriculture Organization of the United Nations, Rome

Joubin L (1894) Céphalopodes d'Amboine. Rev Suisse Zool Ann Mus Hist Nat Genéve 2;23-64

Kasugai T (2000) Reproductive behavior of the pygmy cuttlefish Idiosepius paradoxus in an aquarium. Venus (Tokyo) 59:37-44 
Kasugai T, Ikeda Y (2003) Description of the egg mass of the pygmy cuttlefish, Idiosepius paradoxus (Cephalopoda: Idiosepiidae), with special reference to its multiple gelatinous layers. Veliger 46:105-110

Lindgren AR, Giribet G, Nishiguchi MK (2004) A combined approach to the phylogeny of Cephalopoda (Mollusca). Cladistics 20:454-486

MacPherson JH (1966) Port Philip survey 1957-1963. Mollusca. Mem Natl Mus Vic 27:239-250

Moynihan M (1983) Notes on the behavior of Idiosepius pygmaeus (Cephalopoda: Idiosepiidae). Behaviour 85:42-57

Nabhitabhata J (1994) Rearing of Thai pygmy cuttlefish, Idiosepius thailandicus Chot., Okut. \& Chait., I.: some biological aspects. Tech Pap 13/1994. Rayong Coastal Aquaculture Station, Coastal Aquaculture Division, Department of Fisheries, Bangkok

Nabhitabhata J (1998) Distinctive behaviour of Thai pygmy squid, Idiosepius thailandicus Chotiyaputta, Okutani \& Chaitiamvong, 1991. Phuket Mar Biol Cent Spec Publ 18:25-40

Nabhitabhata J, Suwanmala J (2008) Reproductive behaviour and cross-mating of two closely related pygmy squids Idiosepius biserialis and Idiosepius thailandicus (Cephalopoda: Idiosepiidae). J Mar Biol Assoc UK 88: 987-993

Nabhitabhata J, Suwanmala J, Tasanasuwan P (2006) Are Idiosepius biserialis Voss, 1972 and I. thailandicus Chot., Okut. \& Chai., 1991 the same species: reproductive behaviour evidence? In: Moltschaniwskyj NA, Pecl GT, Semmens J, Jackson GD (eds) Cephalopod International Advisory Council Symposium 2006. Hobart, p 89 (Abstract)

Nesis KN (1987) Cephalopods of the world: squid, cuttlefishes, octopuses, and allies. T.F.H. Publications, Neptune City, NJ

Nesis K, Katugin ON, Ratnikov AV (2002a) Kto eto k nam priplyl takoj malenki? Chemistry Life 7:54-56

Nesis K, Katugin ON, Ratnikov AV (2002b) Pygmy cuttlefish Idiosepius paradoxus (Ortmann, 1888) (Cephalopoda)first record of Idiosepiidae in Russian seas. Ruthenica 12:81-84

Norman MD, Reid A (2000) A guide to squid, cuttlefish and octopuses of Australasia. CSIRO Publishing, Collingwood, Victoria

Nürnberger S, von Byern J, Klepal W (2006) Problems concerning the morphological classification of Idiosepius. In: Moltschaniwskyj NA, Pecl GT, Semmens J, Jackson GD (eds) Cephalopod International Advisory Council Symposium 2006. Hobart, p 91 (Abstract)

Ortmann A (1888) Japanische Cephalopoden. Zool Jahrb 3: $639-670$

Posada D, Crandall KA (1998) MODELTEST: testing the model of DNA substitution. Bioinformatics 14:817-818

Ronquist F, Huelsenbeck JP (2003) MrBayes 3: Bayesian phylogenetic inference under mixed models. Bioinformatics 19:1572-1574

Sasaki M (1921) On an adhering habit of a pygmy cuttlefish, Idiosepius pygmaeus Steenstrup. Annot Zool Jpn 10: 209-213

Sato N, Awata S, Munehara H (2009) Seasonal occurrence and sexual maturation of Japanese pygmy squid (Idiosepius paradoxus) at the northern limits of their distribution. ICES J Mar Sci 66:811-815

Sato N, Kasugai T, Munehara H (2008) Estimated life span of the Japanese pygmy squid, Idiosepius paradoxus from statolith growth increments. J Mar Biol Assoc UK 88:
391-394

Shigeno S, Yamamoto M (2002) Organization of the nervous system in the pygmy cuttlefish, Idiosepius paradoxus Ortmann (Idiosepiidae, Cephalopoda). J Morphol 254:65-80

Steenstrup J (1881) Sepiadarium and Idiosepius, two new genera of the family of Sepia. With remarks on the two related forms Sepioloidea d Orb. and Spirula Lmk. K Dan Videns Selsk Biol Skrift 6:211-242

Steenstrup J (1887) Notae teuthologicae, No. 7. Offprint from: Oversigt over det Kongelige Danske Videnskabernes Selskabs Forhandlinger. Høst \& Søn, Copenhagen

Strugnell J, Norman MD, Jackson J, Drummond AJ, Cooper A (2005) Molecular phylogeny of coleoid cephalopods (Mollusca: Cephalopoda) using a multigene approach; the effect of data partitioning on resolving phylogenies in a Bayesian framework. Mol Phylogenet Evol 37: 426-441

Suwanmala J, von Byern J, Nabhitabhata J (2006) Observation of Idiosepius pygmaeus (Cephalopoda, Idiosepiidae) at Klong Bangrong, Phuket Island, Thailand. Res Bull Phuket Mar Biol Cent 67:49-51

Swofford DL (2002) PAUP: phylogenetic analysis using parsimony (and other methods). Version 4.0b8. Sinauer Associates, Sunderland, MA

> Takumiya M, Kobayashi M, Tsuneki K, Furuya H (2005) Phylogenetic relationships among major species of Japanese coleoid cephalopods (Mollusca: Cephalopoda) using three mitochondrial DNA sequences. Zool Sci (Tokyo) 22:147-155

Thompson JD, Gibson TJ, Plewniak F, Jeanmougin F, Higgins DG (1997) The CLUSTAL_X windows interface: flexible strategies for multiple sequence alignment aided by quality analysis tools. Nucleic Acids Res 25: 4876-4882

Tracey SR, Steer MA, Pecl GT (2003) Life history traits of the temperature mini-maximalist Idiosepius notoides (Cephalopoda:Sepioidea). J Mar Biol Assoc UK 83:1297-1300

von Boletzky S (1995) The systematic position of the Sepiolidae (Mollusca: Cephalopoda). Bull Inst Oceanogr (Monaco) 16:99-104

von Byern J, Klepal W (2007) Occurrence of Idiosepius pygmaeus (Cephalopoda, Idiosepiidae) in Indonesian waters. Ann Nathist Mus Wien Ser B Bot Zool 108:137-144

von Byern J, Klepal W (2010) Re-evaluation of taxonomic characters of Idiosepius (Cephalopoda, Mollusca). Malacologia 52:43-65

von Byern J, Marwoto RM (2009) Occurrence of Idiosepius (Mollusca: Cephalopoda) in Indonesian waters. J Biol Indones 6:13-23

von Byern J, Nürnberger S, Shigeno S (2005) Distribution pattern of a minimalist - new records for Idiosepius biserialis (Idiosepiidae, Cephalopoda). In: Kostak M, Marek J (eds) 2nd Int Symp 'Coleoid cephalopods through time'. Institute of Geology and Palaeontology, Faculty of Science, Charles University, Prague, p 38-43

von Byern J, Rudoll L, Cyran N, Klepal W (2008) Histochemical characterization of the adhesive organ of three Idiosepius spp. species. Biotech Histochem 83:29-46

- Voss GL (1962) South African cephalopods. Trans R Soc S Afr 36:245-272

> Yamamoto M, Shimazaki Y, Shigeno S (2003) Atlas of the embryonic brain in the pygmy squid, Idiosepius paradoxus. Zoolog Sci 20:163-179

Yamamoto T (1942) On the distribution of cephalopods in Korea. Venus (Tokyo) 11:125-133

Submitted: October 25, 2010; Accepted: May 10, 2012

Proofs received from author(s): September 24, 2012 